\title{
The value of Magnetic Resonance Imaging (MRI) in the Follow-up Management of Spinal Injury
}

\author{
P. Sett, MS, FRCS (SN), ${ }^{1}$ H. Alan Crockard, FRCS ${ }^{2}$
}

${ }^{I}$ Thorn Research Fellow, ${ }^{2}$ Consultant Neurosurgeon, The Department of Surgical Neurology, The National Hospitals for Nervous Diseases, Maida Vale, London W9 $1 T L$, UK.

\section{Summary}

Twenty-seven patients with spinal injury have been studied with follow-up Magnetic Resonance Imaging (MRI). MRI has helped (a) to determine the extent of cord injury; (b) to detect continuing compression to the spinal cord; (c) to discover unexpected pathologies and most importantly $(d)$ to detect the development of post traumatic syrinx. MRI was most valuable in patients with post-traumatic syrinxes to evaluate any changes in the size, and, in those who had a shunting procedure, to assess the efficacy of the procedure.

$M R I$ also aided in planning complicated one stage operations by giving a 'complete' picture of the injury inflicted to the vertebrae, soft tissue structures and the spinal cord.

As well as advantages in clinical audit it makes financial sense. It provides more information than CT myelography and is non-invasive.

When compared to the cost of neurological deterioration it is much more cost effective to follow-up spinal injury patients with MRI. It is the authors' contention that after the acute phase all patients with spinal injury should have at least one MRI.

Key words: Spinal injury; Magnetic resonance imaging; Post traumatic syringomyelia; Cord compression; Myelomalacia.

The incidence of spinal injury varies in the Western world. Seven hundred and fifty new cases are seen in the UK every year (population 58 million) (Hospital Episodes Statistics 1987). Between 10000 and 12000 new cases are reported in the USA every year (Neuwelt et al., 1989). Most recent figures indicate an incidence of 30 to $32 \cdot 1$ per million per year of the population in the USA (Stover and Fine, 1986). In Australia 400 cases are noted every year (Walsh, 1988), an incidence of 25 per million per year, comparable to America.

In the last decade, tremendous progress has been made in the efficient and advanced management of the acute spinal injury. This has mainly been due to improved resuscitation and multidisciplinary care in trauma centres. The mortality 
for quadriplegics following spinal injury has fallen from $80 \%$ to $6 \%$ (Roye et al., 1988), while that of traumatic paraplegia has been reduced from 30 to $2 \%$. The life expectancy of the disabled from spinal injury has also dramatically increased. The financial implications of this are staggering, for example, medical costs and lost earnings may amount to 1.5 million dollars per person per year (Roye et al., 1988).

In the UK there are now 10000 disabled survivors of spinal injury and with increasing longevity, this number is increasing (Bradshaw, 1990). A certain number of spinal injury patients experience neurological deterioration months or years after initial trauma. The exact proportion is unknown but one study estimated that it may occur in 2\% per year of the injured (Piepmeier and Jenkins, 1988).

Deterioration is a catastrophe, both mentally and physically. For the particular patient concerned such an event may mean that from being mobile he becomes wheelchair bound or from being an independent useful member of the community he becomes completely dependent. Deterioration may result from instability, persisting compressive pathologies or from the development of a syrinx. The cost to the nation of such deterioration may well run into thousands of pounds for an individual case and millions for the paraplegic community as a whole.

Following the acute phase, reassessment by clinical examination and conventional investigations may not help the clinician to predict which patients are likely to deteriorate.

Magnetic Resonance Imaging (MRI) has an important role to play; it is a noninvasive investigation which has superior ability to image the bony components of the vertebral column, the soft tissue structures in and around it and the spinal cord, throughout its entire length (Quencer et al., 1986).

We have considered MRI essential in the management of the patients because:

(i) it provides the clearest total picture of the injury to the spine and the spinal cord

(ii) It can detect continuing compression of the spinal cord

(iii) it demonstrates post traumatic syrinx before there are clinical signs

(iv) it also provides objective evidence of the successful treatment of a syrinx

(v) by demonstrating bone, ligament and cord pathology the fullest information is available for surgical planning of stabilisation, decompression and syrinx drainage procedures.

This paper presents our experience of 27 patients with spinal injuries who have been investigated and managed after the acute phase.

\section{Demography}

Twenty-seven patients were referred to this department for evaluation and were specifically studied with MRI. All had one MRI but the majority of patients have had further MRI in their follow-up. They were referred either because of clinical deterioration or because of the development of new clinical symptoms and signs; some were referred for an opinion regarding their prognosis.

The patients ranged from 6 to 83 years. Eighteen were males and 9 females. The cause of injury varied. Ten cases resulted from RTA; 8 from falls; 2 from sporting injuries viz. diving and high jump injuries. Penetrating injuries (stab injury and impalement by a knitting needle) were the cause in 2 cases. Two cases resulted 


\section{CAUSES OF SPINAL INJURY}

\section{Total $=27$}

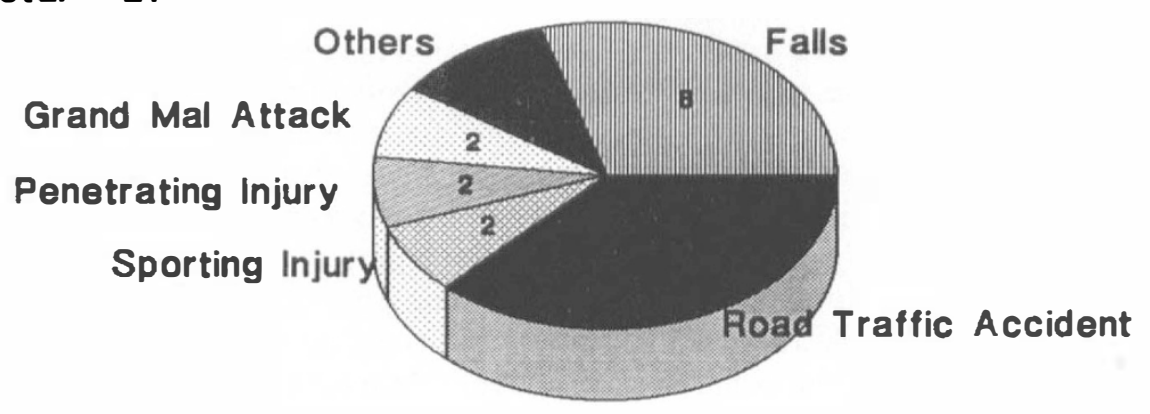

Figure 1 A pie diagram showing the causes of injury.

\section{LEVEL OF SPINAL INJURY}

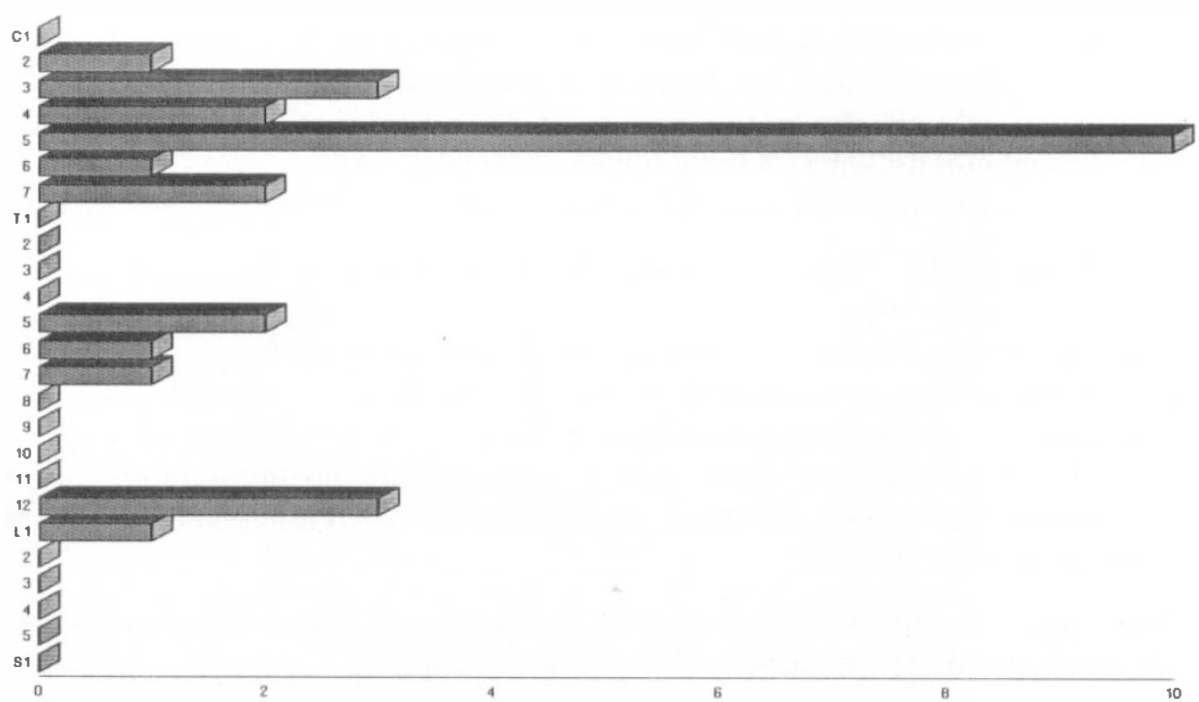

Figure 2 The level of spinal injury in our series.

from grand mal attacks. Finally, 1 case each was the result of osteopathic manipulation, blast injury and an airport accident (Fig. 1). The level of spinal injury is shown in Figure 2.

Thirteen were quadriparetic, 10 paraparetic. Two cases had root compression and 1 case presented with a Brown Sequard's syndrome. One was asymptomatic.

Nineteen out of the 27 patients had surgical intervention either to relieve spinal compression, correct deformity and instability or to treat spinal cord pathology. 


\section{Results}

The initial and follow-up MRI studies were evaluated and for the purpose of this article, the results have been divided into four groups. The clinical conditions were carefully evaluated and have been represented by their Frankel grading (Frankel $e t$ al., 1969).

Group I-Where MRI helped in determining the extent of cord injury

There were 8 patients in this group whose details are summarised in Table I.

The first 2 patients had complete transections of the cord without any syrinx formation. The skeletal injury was stable (Fig. 3). No further change in their clinical condition was expected.

Three cases had incomplete injury; recovery was therefore possible and this occurred in Case 3. His clinical condition improved from Grade A to Grade D. In the fourth and fifth patient no further improvement took place. Follow-up scans on these 2 patients showed that the cord distal to the injury had become atrophic. Case 5 developed a focal cyst at the site of injury to the cord. Revascularisation of the

Table I Where MRI helped in determining the extent of cord injury

\begin{tabular}{lcccc}
\hline Patient & Age/Sex & Cause & Level & MRI \\
\hline 1 & $36 \mathrm{M}$ & RTA & C5/C6 & Complete transection \\
2 & $29 \mathrm{M}$ & Fall & D12/L1 & Complete transection. Small cyst \\
3 & $20 \mathrm{M}$ & Stab & D5/D6 & Incomplete transection \\
4 & $6 \mathrm{M}$ & Stab & C4/C5 & Incomplete transection \\
5 & $30 \mathrm{M}$ & RTA & C4/C5 & Incomplete transection, cyst \\
6 & $41 \mathrm{~F}$ & RTA & C5/C6 & Intact cord, contusion \\
7 & $34 \mathrm{~F}$ & Epileptic & C6/C7 & Intact cord, oedema \\
8 & $36 \mathrm{M}$ & RTA & C5/C6 & Intact cord \\
\hline
\end{tabular}

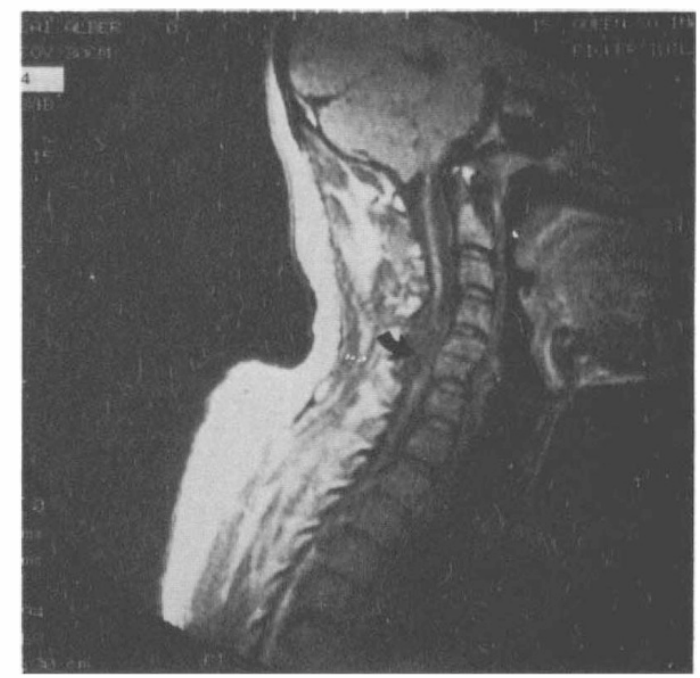

Figure 3 T1 weighted image (TR/TE $500 / 40 \mathrm{msec}$ ) of case 1 . Arrow indicating complete transection of the cord at C5/C6 level. 
cord was carried out by omental grafting. It is too early to assess any benefit from this procedure.

In 3 patients the cord was intact. Case 6 had a contused central cord on initial MRI. Six months later a follow-up MRI showed that her cord was normal. In Case 7 there was extensive oedema of the cord above and below the level of injury. This case has been discussed below.

Case 8 had all the features of Brown Sequard's syndrome from a cervical injury in 1970. In April 1989 he had a fall with exacerbation of his signs and also right brachialgia. MRI showed some compression at $\mathrm{C} 5 / \mathrm{C} 6$ without any cord changes. In the absence of oedema, haematoma, atrophy or hemisection, the cause of his clinical presentation was considered to be vascular.

Illustrative Case 7. This was a lady who was a severe known epileptic, was found to be completely quadriplegic following grand mal attack. Skeletal X-rays of the cervical spine demonstrated dislocation of $\mathrm{C} 6 / \mathrm{C} 7$ vertebrae with over-riding of the facet joints. She was treated by cervical traction. On the seventh day she became drowsy, with lower cranial nerve involvement and bilateral loss of pin prick sensation in the trigeminal distribution. MRI (Fig. 4) showed that even though there was no fracture, the entire ligamentous complex had been disrupted. The cord was

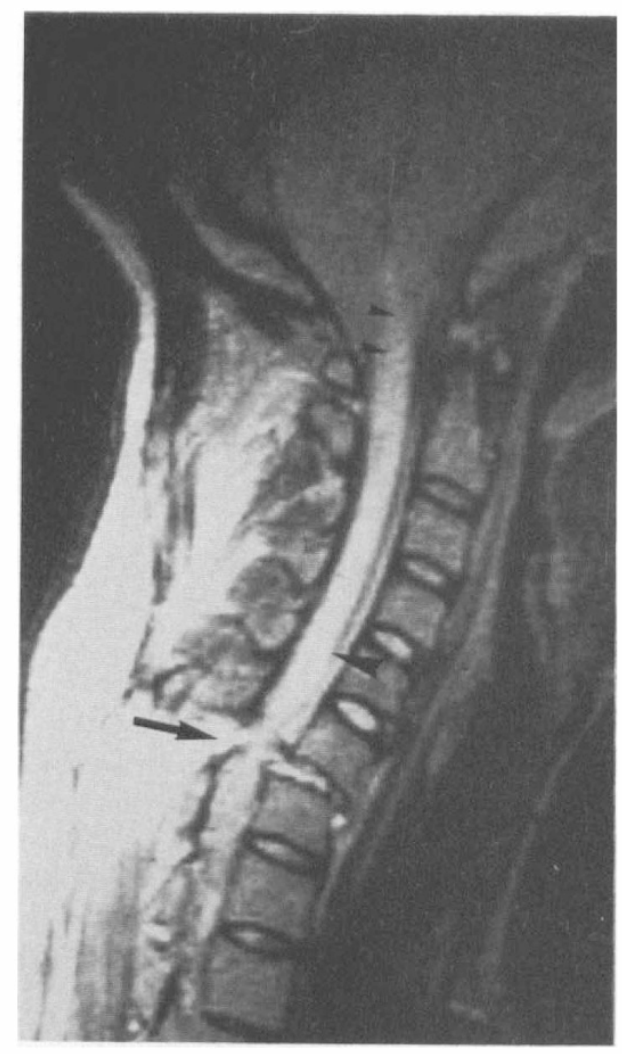

Figure 4 T1 weighted image (TR/TE 500/40 msec) of case 7. Arrow showing C6/C7 dislocation with complete ligamentous rupture. Large arrowhead showing gross oedema of cord. Small arrowhead indicates oedema extending into brain stem. 
Table II Where MRI revealed the extent of cord compression

\begin{tabular}{ccccccc}
\hline & & & & \multicolumn{2}{c}{ Frankel Grade } \\
Patient & Age/Sex & Cause & Level & MRI & Pre-op & Post-op \\
9 & $35 \mathrm{M}$ & RTA & C3/C4 & Canal steonsis & A & D \\
10 & $83 \mathrm{~F}$ & Fall & C3/C4 & Spondylosis oedema & C & D \\
11 & $19 \mathrm{M}$ & Diving & C7/T1 & Fracture dislocation & D & E \\
12 & $58 \mathrm{~F}$ & Manipulation & C5/C6 & Ac. disc prolapse & E & E \\
13 & $47 \mathrm{M}$ & Fall & C5/C6 & Ac. disc prolapse & D & E \\
14 & $47 \mathrm{~F}$ & Fall & D12 & Burst fracture & E & E \\
\hline
\end{tabular}

not transected, but there was extensive oedema above and below the site of injury with the proximal oedema extending up to the brain stem. This explained her drowsiness and cranial nerve involvement. The oedema extended distally well into the dorsal region. As the cord was intact, it was possible that her deficit was temporary and was aggravated by movement at the site of dislocation. Thus the cervical spine was stabilised by Halifax clamps and bone graft (Crockard and Ransford, 1990). This procedure was preferred to anterior fusion for her, because immediate stabilisation was required in case she had another major epileptic fit.

\section{Group II-Where MRI revealed the extent of cord compression}

Persisting compression to the spinal cord was noted in 6 patients. Their details have been summarised in Table II.

In 5 out of the 6 patients, there was spinal cord compression; in 1 patient there was root compression.

In the first 2 patients there was a cord injury without fracture dislocation. Both had severe cervical spondylosis. In Case 10, images of the cord showed severe oedema of the cord above and below the site of maximum compression at $\mathrm{C} 3 / \mathrm{C} 4$ due to infolded ligamentum flavum. A laminectomy and stabilisation with Hartshill rectangle was chosen to decompress and stabilise the spine in this patient. She improved rapidly (Frankel Grade C to D).

In patient Case 11, an Olympic high board diver, injury to the neck had resulted in spasticity to the lower limbs. MRI in addition to revealing skeletal injury, showed extensive damage to the ligaments. The interspinous ligament was completely disrupted. Stabilisation was achieved by anterior vertebrectomy and 'keystone' grafting.

In patients number 12 and 13 there was an acute disc prolapse. Excellent results were obtained immediately after anterior cervical discectomy (a Smith Robinson procedure) (Robinson and Smith, 1955). The injury of Case 12 had resulted from an osteopathic manipulation. In Case 13 there were cord changes in the form of focal hyperdense signal opposite the site of compression. This was interpreted as either ischaemia or focal oedema.

In patient Case number 14, there was a burst fracture of D12 which had resulted from a fall. Compression of the conus was clearly seen in the MRI. Decompression was achieved by a thoraco-abdominal transdiaphragmatic approach. The impacted fragments were removed and a strut graft obtained from the iliac crest was inserted. 


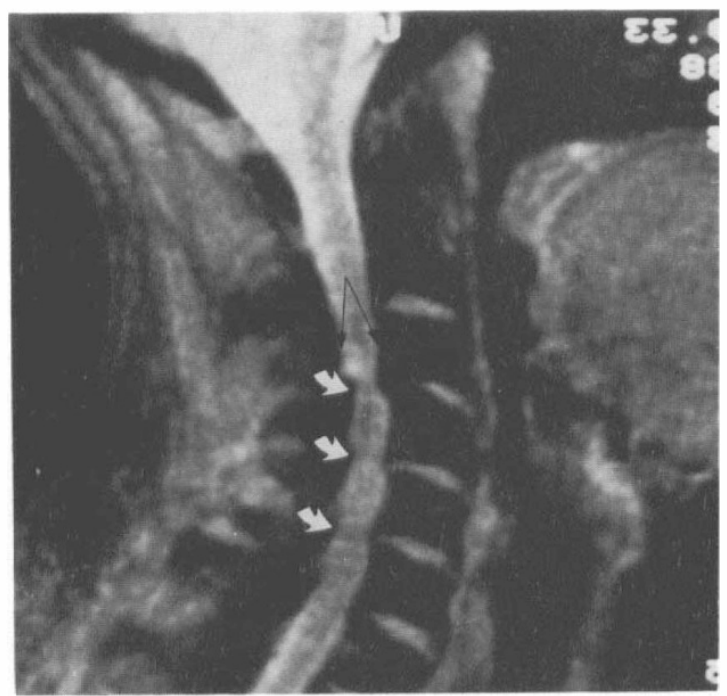

Figure 5 T2 weighted image (TR/TE $2000 / 85 \mathrm{msec}$ ) of case 9 . Black arrows indicate spondylotic canal stenosis. White arrows show hypertrophy and infolding of ligamentum flavum at multiple levels.

There were good results following all the surgical procedures without major complications.

Illustrative case. Patient, Case number 9 was involved in a road traffic accident in January 1988 and rendered quadriplegic. He had marked cervical spondylosis with a narrow canal and some subluxation at $\mathrm{C} 3 / \mathrm{C} 4$. He was initially treated by cervical traction without any improvement in his clinical condition in the first 6 months. MRI in August 1988 demonstrated the cord pathology (Fig. 5). It was 'pinched' at multiple levels. As a first step he underwent $\mathrm{C} 3 / \mathrm{C} 4$ anterior decompression by vertebrectomy and 'keystone' bone grafting. Three weeks later, the posterior compression was relieved by C2-C7 laminectomy. He improved from Frankel Grade A to $\mathrm{D}$. There had been initial total loss of motor power and a sensory level at C4. When admitted to the spinal unit there had been some recovery with some movement in legs and shoulders. He can now walk and move his arms normally but cannot use his hands.

\section{Group III-In which MRI disclosed unexpected pathologies}

The details of the patients in this group are noted in Table III.

In all patients pathologies were unveiled by MRI that were not suspected after clnical examination. The pathologies precipitated or aggravated the spinal injury and also influenced the management of the cases.

In the first, Case number 15, in whom injury was in the lumbar region, the MRI revealed odontoid fracture with the fractured fragments causing compression of the cord. This lesion had not been visualised by conventional radiographs at the time of initial injury. This case is discussed further below. 
Table III Where MRI disclosed unexpected pathologies

\begin{tabular}{lcccc}
\hline Patient & Age/Sex & Cause & Level & MRI \\
15 & $20 \mathrm{~F}$ & RTA & C2 & $\begin{array}{c}\text { Odontoid fracture } \\
\text { Cord compression } \\
\text { Canal stenosis } \\
\text { Hydromyelia } \\
16\end{array}$ \\
$37 \mathrm{M}$ & Fall & C3/C4 & D6 & $\begin{array}{c}\text { Thinned vertebra } \\
\text { angiolipoma }\end{array}$ \\
\hline
\end{tabular}

Case 16 had spondylotic canal stenosis and, after a minor fall causing cervical hyperextension, developed post traumatic hydromyelia which disappeared following anterior osteophytectomy (Robinson and Smith, 1955). This has been reported in detail elsewhere (Sett et al., 1990).

Case 17 had become paraplegic following a grand mal attack which had resulted in a D6 wedge fracture. MRI revealed an extradural mass behind the cord at the level of the fracture. The lesion had thinned the neural arch and had deformed the body of the vertebra by chronic pressure making it vulnerable to injury. At operation the mass was diagnosed as being an angiolipoma.

Illustrative case. Patient, Case number 15 was involved in a road traffic accident in 1975. She was noted then to have a fracture dislocation of L3 with cauda equina involvement. She had a complete paraparesis. She underwent stabilisation operation and attained Grade $C$ function. In 1988 she developed some spasticity of both upper and lower limbs and MRI revealed fracture of the odontoid peg with neuraxial distortion at the craniovertebral junction (Fig. 6). The fracture was not seen on the original radiographs. A transoral removal of the peg was performed. She improved from Grade C to D.

Group IV-Where MRI aided in the detecting and management of cord cysts and syrinxes

Ten patienis with cysts and myelomalacia have been grouped in Table IVa and the 6 cases with syrinxes in Table IVb.

In the first 2 patients (Table IVa) the cysts were noted opposite the site of injury. Follow-up MRI on these patients did not show any increase in their size and the clinical condition was unchanged. They are being reviewed at regular intervals and have not had syrinx surgery.

In patient Case number 20, early cyst formation was noted with expansion of the cord at the site of injury. The cord was however intact. There was severe vertebral angulation and dislocation at C5/C6. It was decided, in the first instance, to decompress by vertebrectomy and stabilise by 'keystone' grafting. The cyst was not treated but observed with yearly MRI. Two years later there is an increase in the size of the cyst suggesting development of a syrinx. If there is any further increase in the size or clinical signs, then a drainage operation will be performed.

In the last patient, Case number 21, 'pencil-shaped softening' (Jellinger, 1964; Jinkins et al., 1986) of the cervical cord over several segments was seen below the 


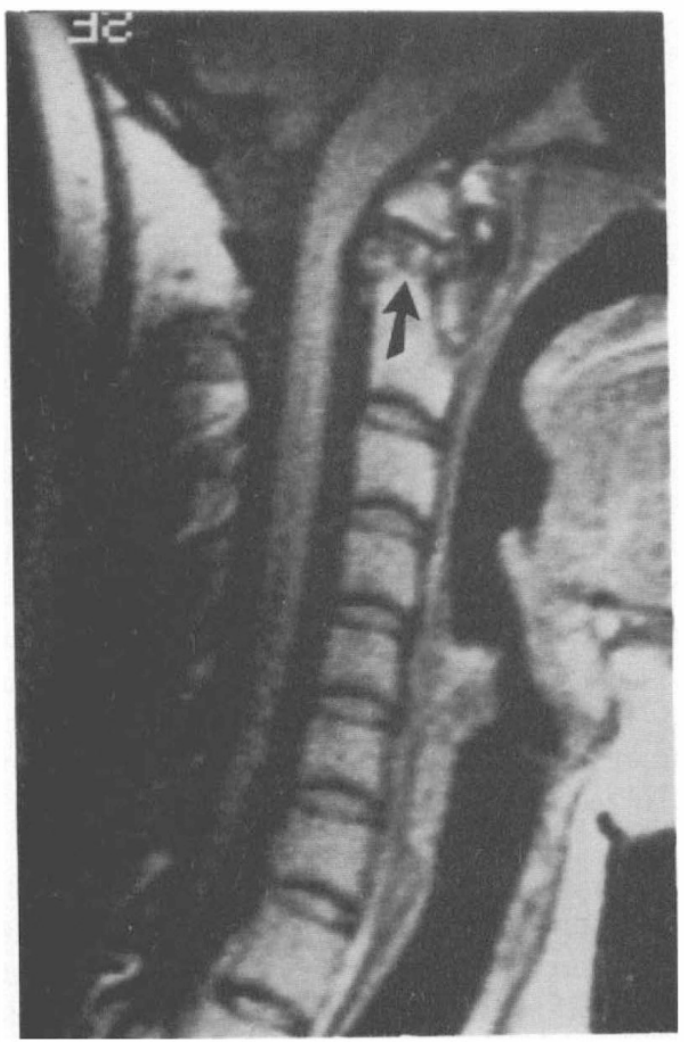

Figure 6 T1 weighted image (TR/TE 500/30 msec) of case 15. Arrow showing odontoid fracture with fractured fragments impinging on the cord.

Table IVa Where MRI helped in detecting and management of cord cysts

\begin{tabular}{lcccc}
\hline Patient & Age/Sex & Cause & Level & MRI \\
\hline 18 & $22 \mathrm{~F}$ & Fall & L1 & Cyst in Conus \\
19 & $16 \mathrm{M}$ & High jump & C6 & Cyst at C6 \\
20 & $17 \mathrm{~F}$ & RTA & C5/C6 & Cyst progression to syrinx \\
21 & $22 \mathrm{M}$ & RTA & C5 & Pencil-shaped softening \\
\hline
\end{tabular}

Table IVb Where MRI helped in detecting and management of syrinxes

\begin{tabular}{|c|c|c|c|c|c|c|}
\hline Patient & Age/Sex & Cause & Level & MRI & $\begin{array}{l}\text { Frankel } \\
\text { Pre-op }\end{array}$ & $\begin{array}{l}\text { Grade } \\
\text { Post-op }\end{array}$ \\
\hline 22 & $20 \mathrm{M}$ & Mcle Acc. & $\mathrm{C} 5 / \mathrm{C} 6$ & Large cervical syrinx & A & $\mathrm{D}$ \\
\hline 23 & $35 \mathrm{M}$ & Mcle Acc. & $\mathrm{D} 12 / \mathrm{L} 1$ & Syrinx C2-D12 & $\mathrm{C}$ & $\mathrm{D}$ \\
\hline 24 & $23 \mathrm{~F}$ & Fall & D7 & $\begin{array}{c}\text { Double-barrelled } \\
\text { syrinx } \quad \text { C2-D7 }\end{array}$ & $\mathrm{C}$ & $\mathrm{D}$ \\
\hline 25 & $39 \mathrm{M}$ & Mcle Acc. & $\mathrm{C} 7 / \mathrm{T} 1$ & Syrinx C4-D3 & $\mathrm{C}$ & $\mathrm{D}$ \\
\hline 26 & $40 \mathrm{M}$ & Airport Acc. & D8 & Syrinx D8 & $\mathrm{C}$ & $\mathrm{D}$ \\
\hline 27 & $44 \mathrm{M}$ & Bomb injury & $\mathrm{C} 5 / \mathrm{C} 6$ & Syrinx C5-C6 & $\mathrm{D}$ & $\mathrm{D}$ \\
\hline
\end{tabular}


level of injury. This myelomalacia was considered to be resulting from central cord ischaemia. The patient has been treated conservatively.

In Group IVb the first 2 patients had extensive syrinxes. In the first, the evolution of the syrinx was demonstrated by serial MR scan. This case is discussed in detail below. In the second, the whole spinal cord was a bag of fluid yet his clinical status was far better than what was expected from the MRI. The patient had had syringotomy performed 17 years before for an earlier syrinx, but had not had regular follow-up.

In both, syringopleural shunts were inserted with good results.

In patients number 24 and 25 the syrinxes required second operation. The first patient was shunted on the findings of CT myelography, which had demonstrated a syrinx on one side of the cervical cord. She had some improvement in the weakness of her right hand but her left arm weakness and her pain in the upper limbs persisted. MRI showed that the syrinx was 'double-barrelled' and the left sided cavity was not compressed by the shunting procedure. A second shunt was inserted on the left side and she improved from Grade $\mathrm{C}$ to $\mathrm{D}$. In the second patient, the shunt tubing had slipped and required repositioning.

Case 26 had a dorsal syrinx with a D8 wedge fracture causing severe compression of the cord. In this patient a one stage procedure was performed consisting of (1) laminectomy; (2) insertion of shunt; and (3) Hartshill stabilisation. His clinical condition improved from Grade C to D.

Illustrative Case 22. Patient number 22 was involved in a motor cycle accident in May 1985. He sustained fracture dislocation of $\mathrm{C} 5 / \mathrm{C} 6$ with complete paraplegia and partial weakness of the upper limbs. One year after injury he developed severe spasticity of all the limbs and severe spasm in the lower. In May 1986 MR scan showed multiple cystic areas in the cervical cord both below and above the level of injury (Fig. 7a). It also revealed compression of the cord and instability of C5/C6. As a first step he was decompressed and his cervical spine stabilised by vertebrec-
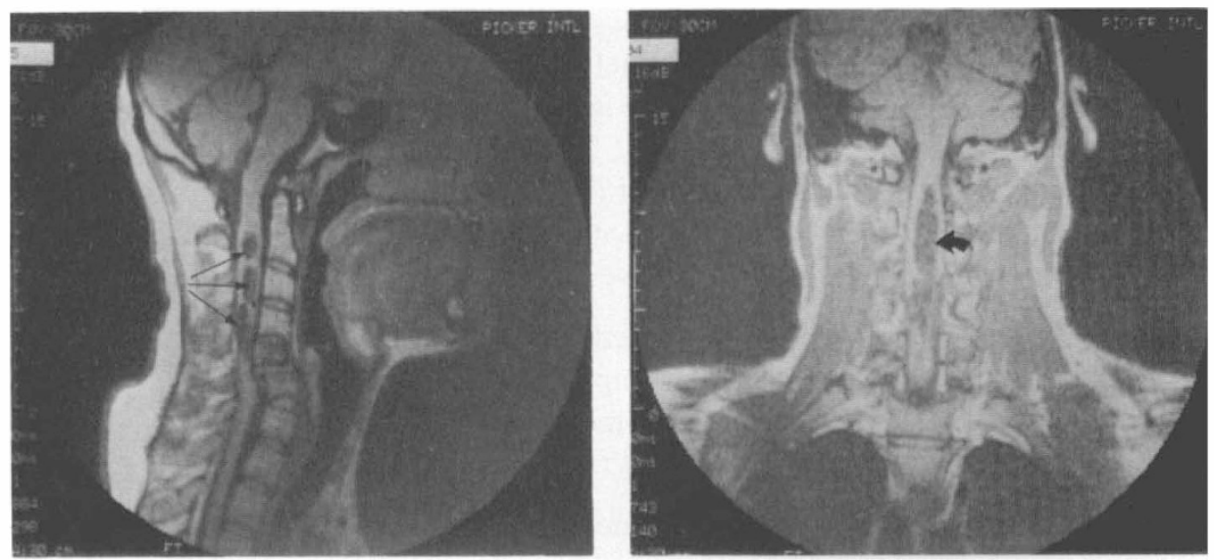

Figure 7a Tl weighted image (TR/TE $500 / 40 \mathrm{msec}$ ) of case 22,1 year post-injury. Arrows point to multiple cysts in the cervical cord.

Figure 7b T1 weighted coronal image (TR/TE 500/40 msec) of case 22, 7 months later. Arrow showing large cervical syrinx resulting from confluence of the cysts in Figure $7 \mathrm{a}$. 
tomy and keystone grafting. It was hoped that the cystic area would not progress, however follow-up MRI in January 1987 revealed that the cyst had enlarged and become confluent (Fig. 7b). A syringopleural shunt was inserted. Post-operatively the spasms in the lower limbs ceased and his spasticity reduced. Frankel grading improved from Grade $\mathrm{C}$ to $\mathrm{D}$. MRI revealed that the syrinx had collapsed but there remains some midcervical focal dilatation. He is being followed-up with yearly MRI.

\section{Discussion}

Tremendous progress has been made in the management of spinal injuries (Stover and Fine, 1986) with significant improvement in the longevity and quality of life (Yarkoney et al., 1987). For the increasing and ageing population of the victims of spinal cord injury, the challenge of those involved in their care, in the next decade, is to prevent further deterioration.

It was believed originally that progressive neurological deterioration was rare (Griffiths and McCormick, 1981; Quencer, 1988; Shannon et al., 1981; Stevens et al., 1985). Piepmeier et al. (1988) have found this to be $12.5 \%$ over 5 years; $10 \%$ of spinal cord injuries deteriorate from Frankel Grading B to A in the first year (Stover and Fine, 1986). Taking into account the existing number of disabled persons from spinal cord injury (250 000 in the USA) (Ergas, 1985) and 10000 in the UK (Bradshaw, 1990) this represents a significant number of patients.

The most remediable causes for deterioration are (a) continuing cord compression and (b) development of syrinx. Conventional investigations and even CT myelography has been found to be inadequate in predicting the patients who are likely to deteriorate.

CT scan has other disadvantages; it is an invasive procedure with complications and may require several serial studies at long intervals to delineate a syrinx. Furthermore, the results can be fallacious. Stevens et al. (1985) has shown in his study that contrast had accumulated after CT myelography in only $58 \%$ of surgically proven cysts. It is also now well recognised that contrast may be taken up in areas of myelomalacia giving false positive results.

The most significant advantage of MRI is its ability to demonstrate pathology within the spinal cord which cannot be as well delineated by computed tomography (Beers et al., 1988; Poujanas et al., 1984). MRI allows visualisation of the traumatised cord and of the structures around it (Quencer, 1988). It is also considered to be the investigation of choice for chronically injured spinal cord (Poujanas et al., 1984; Quencer, 1988). In this study we have found it to be helpful:

(i) in determining the extent of cord injury

(ii) in detecting continued cord compression

(iii) in detecting unexpected pathologies

(iv) in detecting and following-up syrinxes and cysts.

A firm diagnosis and clear cut prognosis has tremendous importance to the patient's and his relatives' psychology. It helps them to reorganise, plan and face up to the life after the patient is discharged from the hospital (Meineike, 1985). With adaptation, training and exercises, the patient may gain a great deal independency (Meineike, 1985). The earlier the extent of cord injury is determined, the 
earlier the rehabilitation and occupational therapy can be started. The patient then can also be integrated into the community earlier.

A skeletal X-ray and even a CT myelogram does not provide the surgeon with as much information to assess the soft tissue structures and the spinal cord. MRI allows visualisation of the structures around the cord in greater accuracy and detail (Mathis et al., 1988; Quencer, 1988).

MRI can be invaluable in determining the extent of cord injury for insurance claims and medico-legal opinions. It can help in budgeting and applying for financial help. All this has enormous implications in improving the quality of life for the victims of spinal injury.

We believe that when deterioration has occurred it is already too late for surgical intervention. We emphasise that early in the course of injury, the nature and extent of compression to the intact cord must be determined to select those patients where continuing compression will cause further damage to the cord. Associated skeletal and soft tissue pathology are known to cause symptoms in a spinal cord injury patient (La Haye and Batzdorf, 1988; Lyons et al., 1987). We would favour early surgical decompression and stabilisation.

In patients with pre-existing cervical spondylosis minor injuries to the spine can cause significant cord damage. These may be focal (case no. 13) or generalised (case no. 10). When cervical spondylosis is marked, soft tissue compression can be very significant. This is best assessed by MRI.

In cases where 'pencil-shaped softening', haemorrhage, or cysts are noted, decompression and stabilisation should be carried out from the front with bone only. Stainless steel implants will jeopardise subsequent MRI studies and 'scanner' friendly material will have to be developed (Crockard and Ransford, 1990).

MRI has the ability to visualise the entire spine, spinal cord and the surrounding structures in its entire length. This is ideal for screening these lesions.

The most important and interesting sequel to spinal injury is the development of post traumatic syringomyelia. It has been recognised as being the most significant factor to further deterioration (La Haye et al., 1988; Lyons et al., 1987; Quencer, 1988; Stevens et al., 1985; Vernon et al., 1982). Hallopeau (1871) was the first to describe the post mortem findings of this condition. The incidence of symptomatic syrinxes before the era of MRI was variable, Watson $1 \cdot 1 \%$; Barnett $2 \cdot 03 \%$ (Barnett and Jousse 1973a). MRI is the supreme investigation for detecting post traumatic syrinxes. It is already indicating that the incidence of this condition is much higher. It is certainly being recognised more frequently (Lyons et al., 1987; Ramanauskas et al., 1989). The exact incidence is not yet known but as more and more patients are subjected to MRI the correct figure is bound to emerge.

The natural history of this condition is not known. In this series it has been observed that cysts may progress to syrinx (patient no. 20). Also it has been observed that separate cystic areas within the cord can coalesce to give rise to a large syrinx, as seen in patient number 22 (Figs 7a and 7b). Multiple syrinxes that do not intercommunicate have been noted before (La Haye and Batzdorf, 1988; Vernon et al., 1983). MRI, therefore, has a significant role to play in establishing the natural history.

Before the advent of MRI, there was no investigation which could help the surgeons in formulating a rational treatment of the syrinxes. Studies with CT myelography provided some insight. Vernon et al. (1983) believes that failure to 
operate will sooner or later lead to deterioration. Stevens et al. (1985) has noted that the results of surgery on small syrinxes were more gratifying. MRI has a role in correlating size of the syrinx with neurological function and outcome of surgery and may help to decide the ideal stage for draining a syrinx.

Recent studies with MRI have shown the dynamic pathology of myelomalacia. Early, intermediate and late myelomalacic changes have been recognised in the cord (Ramanauskas et al., 1989). MRI can therefore help to predict those who may progress to a syrinx.

It has been generally believed that syrinxes are more common after thoracolumbar injury than cervical injury. Ratio (9:1) to (1:1) respectively (Griffiths, 1981). In our series there were three cervicodorsal syrinxes, two cervical and one dorsal due to three dorsal and three cervical injuries.

The onset of symptoms in a post traumatic syrinx is extremely variable. Barnett and Jousse (1973b) found this to be 1 to 15 years, while McLean et al. (1973) noted in his series that it varied from 4 months to 15 years. With the advent of CT and MRI, these figures have been found to be much less-1 month to two years (Quencer, 1988). Lyons et al. (1987) found 18 months as being the average. In our study we have found this to be totally unpredictable. In patient 22 and 26 a large syrinx had developed within a year from injury and was symptomatic. In case 23 , however, even with an extensive cervicodorsal syrinx the patient has remained asymptomatic. It is therefore imperative that MRI studies are performed before symptoms appear in order to prevent further damage to the cord. MRI can also play a vital role in monitoring their progress.

Pain is the most common presenting symptom in cases of post traumatic syrinx, while motor weakness is an uncommon symptom (Shannon et al., 1981, Vernon et al., 1983). However, in our cases the majority of patients had both these presenting features. Additional features noted were spasms, increase in spasticity and deterioration of bladder function. We believe that any new symptom developing in a patient with spinal cord injury should alert the clinician to the possibility of a developing syrinx.

MRI can play a vital role in planning surgical treatment. It not only defines the site and extent of the syrinx but also the number of syrinxes present (e.g. doublebarrelled syrinx in patient number 24) or whether there are septae within the cavity (patient no. 23). By giving information about the condition of the injury to the spine, it can help to decide whether a staged procedure of anterior decompression and stabilisation followed by shunting is preferred (patient no. 22) or whether a single operation will be able to deal with both pathologies (patient no. 27). If the fracture had united then one can shunt the syrinx through a laminectomy, without having to worry about stability (patients nos. 24 and 25).

To summarise, the advantages of MRI are:

(i) It is totally non-invasive.

(ii) It can detect and delineate pathologies in the cord, particularly syrinxes, better than any other investigation. This helps to:

(a) chart the progress of these pathologies

(b) establish the natural history of these conditions

(c) monitor the treatment of syrinxes.

(iii) It gives the total picture of the injury, skeletal, soft tissue and spinal cord. 
This helps to:

(a) give a clear cut diagnosis and prognosis

(b) plan management and surgical treatment

(c) predict deterioration.

The disadvantages of MRI that may be raised are:

(i) That it is costly. MRI costs $£ 300$; the alternative investigation, CT myelography costs $£ 250$ plus all the expenditure that attends admission into hospital It is also an invasive procedure and therefore is not devoid of complications which further add to its cost. We therefore consider MRI to be a very competitive and cost effective investigation. The most important financial implication however, is that the cost of MRI is infintismal when compared to the cost the nation has to bear in providing extra resources to combat the extra disability caused by further neurological deterioration affecting the disabled population. The difference between rehabilitating a paraplegic and a quadriplegic is $\$ 11500$ per year per patient (Walsh, 1988). The cost of rehabilitating a quadriplegic in the USA is $\$ 22000$ (Roye et al., 1988). Patients with a C7 lesion can attain functional independence while those with lesions at $\mathrm{C} 5$ and above are completely dependent (Woolsey, 1985). The economics of losing the use of a few more functional segments is obvious.

There is another aspect of deterioration that cannot however be audited, and that is the social and psychological cost to the patient. Loss of self-reliance and functional independence in a disabled person can never be measured. Nor can the loss of occupational status, social contacts and family life.

(ii) Present availability is limited. The significant advantages of MRI have already been discussed and also its cost effectiveness. It is the contention of these authors that the only rational approach to the long term management of the patients with spinal injury is to follow them up with MRI. The answer must be that more MRI facilities should be available for spinal cord injury.

In conclusion, the challenge for the next decade in the management of spinal injury is to prevent deterioration and improve, even further, the quality of life for those disabled. MRI will have a major role to play.

We believe, in an ideal world, all patients with spinal injury should have this study.

\section{Acknowledgements}

The authors wish to thank Dr J. Stevens and Dr B. Kendall for neuroradiological advice and Miss Michelle Green for preparation of the manuscript.

\section{References}

BARNetT HJM, Jousse AT 1973a Syringomyelia as a late sequel to Traumatic Paraplegia and Quadriplegia. In: Syringomyelia. (ed) Barnett HJM, Foster JB, Hudgson P. WB Saunders Company Ltd: London, Philadelphia, Toronto. pp 129-153.

BARNETT HJM, JouSSE AT 1973b Pathology and pathogenesis of progressive cystic myelopathy as a late sequel to spinal cord injury. In: Syringomyelia. (ed) Barnett HJ M, Foster JB, Hudgson P. WB Saunders Company Ltd: Philadelphia, Toronto. pp 179-219.

BEERS GJ, RAQUE GH, WAGNER GG et al. 1988 Acute cervical spine trauma: MR imaging. Fournal of Computer Assisted Tomography 12:5:755-761.

BRADSHaw S 1990 Director, Spinal Injuries Association, London. Personal Communication. 
Crockard HA, RANSFORD AO 1990 Stabilisation of the spine. In: 'Advances and Technical Standards in Neurosurgery'. (ed) L. Symon. Springer-Verlag: Wien. 17:160-188.

ERGAS Z 1985 Spinal cord injury in United States: a statistical update. Central Nervous System and Trauma 2(1):19-32.

FRANKel HL, HANCOCK DO, Hyslop G et al. 1969 The value of postural reduction in the initial management of closed injury of the spine with paraplegia and tetraplegia. Paraplegia 7:179-192.

GRIFFITHS ER, MCCoRMICK CC 1981 Post traumatic syringomyelia (cystic myelopathy). Paraplegia 19: 81-88.

HALlOPEAU FM 1871 Sur une faite e selerose diffuse de al substance grise et strophie muscculaire. Gazz Med Paris 25:183.

Hospital Episode Statistics 1987 Department of Health, Hannibal House, Elephant and Castle, London.

JELLINGER K 1964 Zur morphologie und pathogenese spinaler lasionen bei verletzungen der halswirbelsaule. Acta Neuropathologica (Berl) 3:451-468.

Jinkins JR, BAShiR R, Al-Mefty O, ZUheIR Al-Kawi M, Fox JL 1986 Cystic necrosis of the spinal cord in compressive cervical myelopathy: demonstration by Iopamidol CT-myelography. AfNR 7: 693-701.

LA HAYe PA, BATZdorf U 1988 Post traumatic syringomyelia. Western Journal of Medicine 148(6): 657-663.

Lyons BM, Brown DJ, CaLvert JM, WoOdWARd JMM, WRIEDT CHR 1987 The diagnosis and management of post traumatic syringomyelia. Paraplegia 25:340-350.

MCLEAN DR, MILLER JDR, ALLEN PBR, EzzEDIN SA 1973 Post traumatic syringomyelia fournal of Neurosurgery 39:485-492.

Mathis JM, Wilson JT, BaRnARD JW, Ella-ZELENIK ME 1988 MR imaging of spinal cord avulsion. AfNR 9(6):1232-1233.

MEINECKE FW 1985 Some thoughts about neurological recovery in spinal cord injuries: a philosophical review. Paraplegia 23:78-81.

NeUWelt EA, CoE MF, Wilkinson AM, Avolio EC 1989 Oregon head and spinal cord injury prevention program and evaluation. Neurosurgery 24:(3):453-458.

PIEPMEIER JM, JENKINS RN 1988 Neurological changes following traumatic spinal cord injury. Fournal of Neurosurgery 69:399-422.

Poujanas K, Williams AL, Daniels DL, Haughton VM 1984 Syringomyelia and hydromyelia: magnetic resonance evaluation. Radiology 153:679-683.

QUENCER RM, SHELDON JJ, DonOVAN J et al. 1986 Magnetic resonance imaging of the chronically injured spinal cord. $A \mathcal{F N R}$ 7:457-464.

QUENCER RM 1988 The injured spinal cord. Evaluation with magnetic resonance and intra-operative sonography. Radiologic Clinics of North America 26(5):1025-1045.

Ramanauskas WL, Wilner HI, Metes JJ, LaZo A, Kelly JK 1989 MR imaging of compressive myelomalacia. Fournal of Computer Assisted Tomography 13(3):399-404.

RoBINSON RA, SMITH GW 1955 Anterolateral disc removal and interbody fusion for cervical disc syndrome. Bulletin of the Fohn Hopkins Hospital 96:223-224.

ROYE WP, DuNN EL, Moody JA 1988 Cervical spinal cord injury-A public catastrophe. The fournal of Trauma 28(8):1260-1264.

SETT P, CROCKARD HA 1990 Resolution of cervico-dorsal syringohydromyelia following anterior cervical fusion: a case report. Neuroorthopaedics 9:53-61.

Shannon N, Symon L, Logue V, Cull D, Kang J, Kendall B 1981 Clinical features, investigation and treatment of post traumatic syringomyelia. Fournal of Neurology, Neurosurgery and Psychiatry 44:35-42.

STEVENS JM, Olney JS, Kendall BE 1985 Post traumatic cystic and non-cystic myelopathy. Neuroradiology 27:48-56.

STOVER SL, FINE PR 1986 Spinal cord injury: the facts and figures. The National Spinal Cord Injury Statistical Centre, University of Alabama at Birmingham, Birmingham, Alabama. p 1-64.

STOVER SL, Fine PR 1987 The epidemiology and economics of spinal cord injury. Paraplegia 25: 225-228.

Vernon JD, Silver JR, OHry A 1982 Post traumatic syringomyelia. Paraplegia 20:339-364.

VERNON JD, SILVER JR, SYMON L 1983 Post traumatic syringomyelia: the results of surgery. Paraplegia 21:37-46.

WALSH J 1988 Costs of spinal cord injury in Australia. Paraplegia 26:380-388.

WOOLSEY RM 1985 Rehabilitation outcome following spinal cord injury. Archives of Neurology 42: $116-119$.

YaRkoney GM, Elliot JR, Heinemann AW, Yeongchi W, Katz RT, Lovell L 1987 Benefits of rehabilitation for traumatic spinal cord injury. Multivariate analysis in 711 patients. Archives of Neurology 44:93-96. 